Relatorio

\title{
ACEPTARON AS SOCIEDADES RURAIS EUROPEAS AS POLÍTICAS PAISAXÍSTICAS PÚBLICAS?
}

Pierre Donadieu

École Nationale Supérieure du Paysage de Versailles 

Neste texto pretendo amosar que a produción social e política das paisaxes rurais, no sentido xeográfico da expresión, depende da interacción de dúas forzas: a das invitacións e os requirimentos públicos nacionais ou europeos, segundo os cales cómpre facer uso da noción de paisaxe para construír marcos vitais considerados bens comúns ou públicos, no sentido en que empregan estes termos os economistas; e a dos proxectos e intereses individuais e colectivos dos actores locais, en especial os agrícolas, que teñen como fin producir unha paisaxe en tanto que única consecuencia da influencia económica e territorial que exercen sobre o espazo.

No primeiro caso, existe a promesa de produción dun espazo multifuncional, provisto de valores materiais e inmateriais e percibido como un ben común paisaxístico que se debe transmitir; no segundo, a produción dun territorio agrícola que, en xeral, ten un carácter monofuncional e exclúe os valores non económicos externalizados como biodiversidade, memoria, identidade, beleza, benestar, etc.

As sociedades «rurbanas», que hoxe apenas son de índole agraria, estrutúranse arredor da idea dos bens comúns da paisaxe rural, no primeiro caso, e arredor dun ideal de territorio agrícola que constitúa a base da mera produción de mercadorías, no segundo.

\section{O PROXECTO PAISAXÍSTICO: UNHA REACCIÓN PÚBLICA DIANTE DA RUPTURA DAS PAISAXES RURAIS?}

O proxecto paisaxístico constitúe unha invitación lene ou firme -requirimento- contida nos textos xurídicos -lexislación nacional e convenios internacionais- a facer uso da noción de paisaxe para dotar dun marco regulamentario a produción social e política do espazo. Ata mediados do século XX, en Europa, estas normas designaban, sobre todo, localizacións que debían ser obxecto de 
protección por teren uns valores relacionados coa identidade nacional -os sitios históricos, por exemplo- e, máis raramente, valores naturais -os parques e reservas naturais nacionais ${ }^{1}$.

En 1972, a Convención do Patrimonio Mundial da UNESCO ampliou a escala planetaria a preocupación pola protección das paisaxes notables de tipo cultural e natural. Posteriormente, a Convención Europea da Paisaxe (Florencia, 2000) redefiniu a noción de paisaxe alén do seu ámbito habitual, o das políticas de protección. Para os países que ratificaron esta convención, a paisaxe, como "percepción que teñen as poboacións dunha parte do territorio, cuxo carácter resulta da interacción de factores naturais e/ou humanos», tornouse unha ferramenta de produción social e política de espazos, sendo estes o marco e a base da vida diaria humana e non humana ${ }^{2}$.

Tal ampliación de óptica reviste unha importancia considerable para os países europeos que ratificaron esta última convención. Significa que a idea que cadaquén ten do benestar humano -o propio e o dos semellantes- e do non humano -a vida animal e a vexetal- debe pórse en relación cos caracteres físicos; é dicir, cos atributos perceptibles das contornas en que se desenvolven os seres vivos. Esta nova óptica paisaxística significa, así mesmo, que aqueles que adopten estes principios se adhiren á idea da construción da identidade das paisaxes europeas así producidas. A convención, que emana do Consello de Europa, non di que paisaxes se deben producir, senón como producilas facendo referencia ás calidades e aos valores paisaxísticos que os europeos, sexan individuos ou grupos sociais, designen para estes efectos.

Tal proxecto concírnelles a todas as sociedades rurais das nacións e rexións europeas. Estas últimas víronse afectadas por transformacións das súas paisaxes que foron percibidas de diversos modos segundo os países e as épocas.

\section{As rupturas paisaxísticas rurais}

Unha ruptura paisaxística é unha modificación das paisaxes que lles afecta a aqueles que a perciben. Pode ser brusca, como a desaparición, da noite para a

\footnotetext{
${ }^{1}$ Véxase Donadieu e Scazzosi (Donadieu e Périgord, cap. 3, 2007).

${ }^{2}$ Enténdese por isto que os obxectivos de conservación, restauración e creación de paisaxes lles concirnen tanto ás sociedades humanas como ás poboacións vexetais e animais.
} 
mañá, dunha plantación forestal destruída por un trebón; rápida, como a inducida pola construción dunha liña ferroviaria ou unha autoestrada; ou moi lenta, a semellanza do que ocorre coa penetración urbana no campo, a transformación dun porto pesqueiro en porto de recreo ou a extensión de plantacións forestais polas montañas.

Esta ruptura, que deron por boa, por exemplo, os agricultores progresistas do decenio de 1950, era desexada polos técnicos agrícolas do Estado francés. Tales mudanzas radicais, consideradas destrutivas polos cidadáns que posteriormente repoboaron o espazo periurbano e rural, foron deploradas, e os poderes públicos, iluminados polos expertos, tentaron remediar logo esta situación mediante políticas públicas de conservación e restauración a partir do decenio de 1970 . Nunha época posterior, a Política Agrícola Común pretendeu, desde a década de 1990, atenuar os efectos que ten sobre a paisaxe e o medio natural.

As causas das rupturas lentas deben procurarse nas evolucións demográficas e económicas que aconteceron ao longo do século pasado. Os éxodos rurais cara ás cidades e colonias dos países europeos baleiraron o campo e a montaña da maioría dos seus agricultores e artesáns. Nas rexións de montaña, a diminución da actividade agraria é visible hoxe no abandono da meirande parte das terrazas agrícolas e na diseminación, ás veces masiva, de plantacións naturais e artificiais de coníferas e frondosas. Tanto na periferia das cidades pequenas como na das metrópoles, a periurbanización controlada -Alemaña, Gran Bretaña, Países Baixos- ou máis libre -sur de Francia, Italia, Grecia- fíxose a expensas dos espazos agrícolas e dos agricultores. Por outra banda, a mecanicación permitiu que por todas as partes se intensificase a produción agrícola, o que comportou consecuencias paisaxísticas xulgadas como lamentables polos «rurbanos» ${ }^{3}$-concentracións parcelarias, desaparición de sebes e do pequeno patrimonio rural- e tamén consecuencias ambientais - polución das augas, regresión da biodiversidade.

A toma de conciencia dos efectos nefastos das políticas agrícolas produciuse grazas á información difundida polos medios de comunicación, xa que permitiu que todo o mundo comprendese o sentido da ruptura paisaxística, tanto máis na medida en que a sociedade rural se tornaba máis urbana e menos agrícola ou

\footnotetext{
${ }^{3}$ Os «rurbanos» son habitantes permanentes ou temporais do campo, que teñen unha actividade ou un emprego na cidade. Son asemade rurais, pola súa localización, e urbanos, polas súas actividades e a súa cultura.
} 
agraria; isto desembocou -ou está a desembocar, nos últimos países europeos que seguiron esta evolución, como Portugal- nunha situación paradoxal:

Por unha banda, unha maioría da poboación cidadá que vive no campo, traballa na cidade do lado -commuters- e desexa manter un estilo de vida san, agradable, equipado e accesible; pola outra, os empresarios agrícolas, preocupados por obter unha rendibilidade económica e remisos a aplicar as normas ambientais e paisaxísticas que poidan poñelos nunha situación de desvantaxe con respecto á competencia.

Ademais, por unha parte están tamén as persoas que posúen unha segunda vivenda no campo e os turistas que van á procura dunha ruralidade mítica, de identidades paisaxísticas desaparecidas ou confinadas en reservas, e dun fácil acceso ao campo; pola outra, os agricultores, horticultores e gandeiros, que diversifican a súa produción e recorren ao pluriemprego, mais que non poden decidirse a vivir máis da prestación de servizos agrícolas á colectividade -especialmente servizos de tipo paisaxístico e ambiental- que da venda dos seus produtos.

Por que tal contradición? É que xa non lles resulta posible aos habitantes e ás poboacións que circulan polo campo percibir as paisaxes rurais tal e como se producen, e non tal e como as soñan ou como lles prometen as axencias turísticas e os medios de comunicación? Todo depende de como consideren o mundo rural e das «lentes paisaxísticas» que filtren a súa percepción.

\section{Catro maneiras de percibir as paisaxes rurais}

A primeira é herdeira da historia da pintura paisaxística e do nacemento do turismo, e presenta a paisaxe en tanto que imaxe dotada ou non de atributos estéticos, como propoñen os cadros ou as fotografías para admiración de quen segue as descricións pintorescas das guías turísticas. Así xorden escenas nostálxicas de granxas vellas, gandos apracibles, carreiros campestres e avesíos, antigos cruceiros, castelos de outrora, regatos calmos que inspiran o paseante do campo. Estas visións procuran a imaxe "escénica", atractiva e fascinante. Nacidas nos museos, do contacto coas obras pictóricas e as fotografías nostálxicas, son externas ao país agrario, non reteñen del máis que a superficie -brillante ou deslucida- e denuncian a perda de memoria visible do campo. Tales olladas non son innatas: están «formadas» pola cultura das imaxes que circulan polo mundo dos 
medios e nelas fundaméntase unha parte dos mercados turístico e residencial. A súa tendencia é a de esperar que o campo se torne un inmenso parque público que sexa fonte de emocións estéticas e de sensacións de benestar; un punto no cal quen así o agarda adoita ficar decepcionado, xa que o campo agrícola non está concibido para se converter nun parque de atraccións.

A segunda categoría de percepcións refírese ás visións «informadas» pola influencia das ciencias, as artes e a erudición dos guías turísticos, que fan que se interpreten as paisaxes rurais a través da sapiencia dos historiadores, xeógrafos e arqueólogos, xeólogos, botánicos ou ornitólogos, agrónomos, etnólogos e sociólogos, arquitectos e urbanistas. Tantos coñecementos que levan a comprender o que se investiga e se ve, que sinalan os desafíos económicos, ambientais, sociais e culturais da evolución das paisaxes... Cómpre dicir que os turistas atraídos por estas visións teñen máis relación co turismo cultural e co ecoturismo. A estes viaxeiros curiosos preocúpalles persoalmente a orixe do que perciben, o que non exclúe que vaian á procura de espectáculos fascinantes. Desexan comprender o funcionamento dunha reserva natural ou dunha marisma salina, a arquitectura dunha capela ou a orixe dunha localización arqueolóxica. O campo constitúe para eles un mundo perceptible de signos que cómpre descifrar, cuxas formas agrícolas quedan ás veces no esquecemento.

Ao contrario do que acontece coas dúas categorías precedentes de visións, externas ás terras que se atravesan, a terceira óptica élles interna. Trátase das percepcións visuais dos produtores de paisaxes rurais: enxeñeiros forestais, agricultores, gandeiros ou horticultores, mais tamén profesionais do litoral, como os dedicados ao cultivo de moluscos. Por naceren no propio lugar, están vinculadas aos territorios de cada produtor: os campos ao dono dunha explotación agrícola, a plantación ao silvicultor, os invernadoiros ao horticultor, mais tamén os medios naturais ao naturalista, as estradas ao enxeñeiro e mesmo os carreiros ao paseante ou as pistas ao xinete. Estas percepcións son as dos «iniciados» á vida local, coa que normalmente están familiarizados. Adoita tratarse de habitantes permanentes, mais, se son residentes secundarios, a súa visión híbrida toma prestados diversos elementos, segundo a duración e a intensidade da súa ancoraxe local, das visións formadas ou das informadas. Ás veces, algúns turistas, na procura da autenticidade das paisaxes rurais, buscan a compaña de grandes coñecedores das rexións agrícolas ou vitícolas. 
A última categoría, a dos «corpos iniciados», constitúe unha extensión da anterior, que pode atanguer a todas as demais. A súa experiencia do espazo non é nin simplemente contemplativa, nin sabedora, senón sobre todo corporal. Na súa calidade de afeccionados á marcha, á equitación, ao cicloturismo, á vela, ao rafting, ao surf ou ao barranquismo, senten en primeiro lugar no seu co rpo o espazo que atravesan, con dor ou con alegría. O espazo é, fundamentalmente, un lugar de busca de sensacións e emocións: velocidade, vertixe, dor, pracer, inquietude, medo, etc. Os intentos de autosuperación, a asunción de riscos e a procura dos límites físicos alimentan os desafíos impostos aos outros e a un mesmo. As paisaxes rurais e litorais tórnanse, xa que logo, o marco ou a base de actividades deportivas normais ou extremas, ás veces un pouco ao xeito dos parques de atraccións. Do mesmo modo, pero máis ordinario, estas paisaxes «incorporadas» son tamén as dos agricultores que aran e segan, dos pastores que guían os seus rabaños, dos apicultores que recollen o mel ou dos ornitólogos que observan -agachados tras das canas, como os cazadores- os paxaros migratorios. Nada de imaxes pin torescas, nin de erudición moi sabedora, senón experiencias ordinarias que xeran recordos, referencias, vencellos ou repulsión ante territorios familiares ou descoñecidos.

Todas estas percepcións do espazo poden atinxir, por separado ou non, a mesma persoa, aínda que as prácticas turísticas e de ocio adoiten unir aqueles que se dedican ao mesmo. Un agricultor ou un cazador poden ser tamén, en lugares diferentes dos da caza ou do campo, turistas estetas ou entendidos, e deportistas apracibles ou extremos.

Non obstante, a cuestión que nos interesa aquí é a de saber como estas percepcións -en especial estas olladas- se asocian ou se exclúen nun mesmo lugar. As visións internas dos iniciados e dos «incorporados», que viven os seus territorios de prácticas -o espazo vivido dos xeógrafos-, teñen tendencia a excluír ou a incluír as visións externas dos estetas e eruditos? Non se dan con frecuencia tensións sociais e conflitos?

\section{Relacións pacíficas ou conflitivas?}

Diante dos mandatos paisaxísticos públicos - preocuparse pola calidade do estilo de vida ou do benestar humano e non humano-, os catro grupos sociais cuxas percepcións da paisaxe acabamos de caracterizar adoptan actitudes moi diferentes. 
No mundo minoritario dos agricultores e empregados forestais que producen o esencial das paisaxes rurais, a creación de regras e normas de obrigado cumprimento provoca dous tipos de comportamentos. Os empresarios agrícolas e forestais, apegados aos valores liberais do mercado de bens, adoitan mostrarse hostís ou desconfiados, e rexeitan que a Política Agraria Común (PAC) condicione a concesión de axudas financeiras á súa produción en función de normas de calidade ambiental e paisaxística. Normalmente, non se preocupan de producir gratuitamente os bens comúns da paisaxe, dos cales non poden tirar beneficio ningún e cuxa produción e mantenza non entran no seu proxecto económico -árbores illadas ou integradas en sebes; ribadas, bancais e terrazas; a auga limpa das capas freáticas, fontes e ríos, a fauna avícola ou entomolóxica silvestre, os camiños de acceso público aos espazos agrícolas, etc.-, agás se estes bens -mesmo caros de producir- melloran ou distinguen os seus produtos, como ocorre coa singularidade das terrazas vitícolas das rexións de Denominación de Orixe Controlada. Neste caso, a produción da paisaxe está internalizada pola empresa; non sucede o mesmo coas bolboretas e os paxaros silvestres.

Pola contra, nas rexións litorais e periurbanas, algúns agricultores móstranse dispostos a diversificar os seus ingresos co agroturismo, os servizos pedagóxicos de pesca ou de caza, os viveiros ou a venda directa. Ao ver dos iniciados, estes agricultores, transformados en urbanos, non perciben a paisaxe como algo exclusivo deles, senón que llela abren aos consumidores das rexións urbanas.

En moitos casos, os seus ingresos poden chegar a ser case totalmente urbanos, ata o punto de ficar desligados da produción agrícola. Así ocorre cos dedicados ao hobby farming -agricultura de pracer-, que conservan, sobre todo na área mediterránea, hortos de oliveiras polo simple pracer da produción propia e o autoconsumo. Xa que logo, estas persoas toman prestadas, cada vez máis, as lentes dos ollares formados ou informados para contemplar ou explicar a súa paisaxe interior, con frecuencia pouco comunicable. Outras modifican radicalmente as súas prácticas ao se adherir a requirimentos ambientais, e lánzanse, así, á agricultura ecolóxica ou ao turismo sostible, que implican a aceptación das novas regras do mercado, como no caso do comercio xusto.

No mundo maioritario dos habitantes permanentes do rural que non son agricultores, os mandatos paisaxísticos e ambientais deberían acollerse por unanimidade. En Francia, por exemplo, as normas urbanísticas e arquitectónicas, 
como as que limitan as molestias sonoras ou visuais, son particularmente precisas nas comunas dos corenta e tres parques naturais rexionais. Estas organizacións, tuteladas polo Estado e as rexións, dispoñen desde a Lei de 1993 de cadansúa carta de boa conduta paisaxística, patrimonial e ambiental, á cal recorre o alcalde de cada comuna para se opor aos proxectos que se consideran desviados das normas ou pouco cívicos: paso de liñas eléctricas de moi alta tensión, canteiras, vertedoiros, fábricas contaminantes, autoestradas, urbanizacións, etc.

Ademais destes marcos, en principio exemplares, o agrupamento das comunas en novas colectividades viuse acompañado por plans e cartas paisaxísticos que levan á práctica un amplísimo número de leis, decretos e circulares vinculantes para os propietarios e promotores inmobiliarios que queiran dispor dos seus bens: prohibición de edificar nas ribeiras, servidume de paso litoral, dereito preferente de compra dos conservatorios do litoral, clasificación dos lugares e monumentos históricos, regulamento das concesións de permisos de obra e de demolición, etc.

O alcance destes dispositivos regulamentarios atinxe tanto a conservación do patrimonio histórico e natural como o desenvolvemento turístico e de ocio, a restauración dos lugares degradados - parcelas industriais abandonadas ou activas- ou a creación de novas paisaxes - turbinas eólicas, hoteis, urbanizacións, zonas de actividade comercial e artesanal-, e teñen como obxecto reforzar ou crear o atractivo e a identidade dos territorios rurais a partir de sinais de memoria -lavadoiros, cruceiros, cabanas de pedras secas para habitación temporal, choupanas vitícolas ou pesqueiras, vertedoiros de cascallos da minaría, terrazas vitícolas, árbores senlleiras, lugares relixiosos, etc.-, mais tamén novos -turbinas eólicas, arquitectura innovadora, en especial a de Alta Calidade Ambiental. Ademais, as prácticas de decoración das vilas, como os adornos florais, moi promovidas polos poderes públicos, adoitan ser ben acollidas polos habitantes.

Pola contra, a hostilidade dos residentes cara ao campo desátase cando a acumulación de normas e regras se torna pesada ou lles impide, por exemplo, a innovación arquitectónica. Cando a hiperregulamentación fai uniformes as urbanizacións e crea estilos neorrexionais insípidos, como o bretón, alsaciano, normando, provenzal, poitevino, etc. Cando os adornos florais ou verdes se volven artificiais e disfrazan dubidosas segregacións sociais. Incorporadas, iniciadas, ás veces entendidas, as percepcións da paisaxe son máis ben endóxenas e territorializadas, e adoitan estar afectadas pola síndrome SPAN (Si, Pero Aquí Non). 
A última categoría é a dos residentes secundarios e a dos propietarios dunha segunda vivenda. Aínda que non pasan no campo máis que varias semanas ou meses no ano, adoitan converterse posteriormente en futuros residentes principais cando lles chega a xubilación. Primeiro poñen os lentes do esteta formado e ceden diante do impulso de mercar unha casa de vacacións e, despois, toman prestados os lentes do «incorporado»-ocio externo- e do «informado», e mesmo do «iniciado». Gustan dos mandatos paisaxísticos mentres conserven o marco que eles adoptaron e afasten as actividades indesexables -industrias contaminantes, prácticas agrícolas molestas, caravaning indisciplinado, estradas e turbinas eólicas demasiado ruidosas, etc.-; mais rexeitan os devanditos requirimentos cando lles impoñen excesivos límites para ampliar a casa, cos seus regulamentos sobre a superficie, as formas, os materiais ou cores das fachadas ou as luces. $\mathrm{Na}$ paisaxe -que debe ficar inmobilizada- radica para eles a primeira razón que invocan no caso de se planearen modificacións perceptibles na súa contorna máis próxima -un parque eólico, unha estrada, vivendas... Esta contorna escollida é, ao seu ver, eterna. Toda mudanza contraria aos seus proxectos constitúe irremediablemente un motivo de protesta e de mobilización activa. Toda ruptura do marco escollido é sentida con dor, sobre todo se vén imposta desde fóra.

As sociedades rurais de hoxe xa non teñen moito que ver coas sociedades agrarias de outrora. Influídas pola penetración das culturas urbanas que idealizan o campo, tenden a naturalizar e a normalizar os requirimentos paisaxísticos, como ocorreu na meirande parte dos países do norte de Europa. Estes mandatos permítenlles adaptar o vello marco agrario á sociedade «rurbana» actual; as explotacións agrícolas transfórmanse en casas de campo, residencias, museos ou hoteis, as eiras en xardíns, as pistas agrícolas en sendas de paseo, os estanques, marismas e explotacións en lugares pedagóxicos, os vellos hortos en sitios de recreo, as pistas forestais en itinerarios para practicar a carreira a pé ou a equitación, os campos en parques públicos arborados ou parques de atraccións, os antigos polígonos industriais en restaurantes, estudios cinematográficos ou lugares destinados a exposicións ou ao teatro, etc.

Esta mutación non se fai sen tensións e conflitos entre os que manteñen diferentes puntos de vista, sobre todo entre os empresarios agrícolas que aínda quedan e a maioría dos demais habitantes. Os países agrícolas resístense aínda aos cantos das sereas paisaxísticas. Mais como? 


\section{A GOBERNANZA DAS PAISAXES RURAIS: O RETO DA AUTENTICIDADE}

\section{Un marco híbrido entre cidade e campo}

Nas visións utópicas do campo posmoderno dos paisaxistas urbanistas e arquitectos paisaxistas, a paisaxe converteuse en Europa nunha noción fundamental desde hai máis de vinte anos (Donadieu, 2006b, p. 36-45). Non só se presenta como «un filtro sensorial de enfoque variable» para pensar a cidade horizontal no seu territorio, senón que tamén lles promete a cidadáns e turistas novas imaxes e lugares da vila que xa non separan os espazos rurais ou naturais dos que non o son. Nesta concepción posmoderna das rexións urbanas e rurais maniféstase a preocupación dos arquitectos paisaxistas e dos paisaxistas urbanistas por se erixir en xeradores de proxectos previos á planificación urbanística, e tamén como capataces, xunto con outros, de accións concretas de ordenación espacial das infraestruturas urbanas e rurais.

Ao contrario do que acontece coas industrias, que deixan ruínas tras de si, as actividades agrícolas, xa se sitúen preto ou lonxe das cidades, non morren bruscamente, senón que se transforman devagar. As agriculturas rurais, por diversificación e pluriactividade, tórnanse agriculturas urbanas que se volven cara á cidade e, posteriormente, en agriculturas e xardinarías non comerciais, ata chegaren á etapa final do espazo paisaxístico, que adoita excluír as actividades de produción agrícola. Estas catro etapas espaciais constitúen, xunto coas plantacións forestais e os espazos acuáticos, un patchwork de procesos híbridos -entre natureza e cidade- que producen a infraestrutura material paisaxística da rexión urbana, así como a das súas imaxes.

Para que as actividades agrícolas atopen un lugar normalizado na rexión urbana ou periurbana, é preciso que tanto os poderes públicos como os deseñadores urbanos lles dean unha utilidade e un lugar físico e social que as consagren como bens comúns urbanos, á mesma altura que os parques arborados, as autoestradas urbanas e os cemiterios; mais lembrando que o mercado non produce espontaneamente paisaxes satisfactorias, agás se os encargados das obras públicas e privadas se preocupan diso.

Velaí a razón de que resulte esencial acadar unha alianza entre urbanistas do landscape, os cargos políticos electos e as organizacións agrícolas e xardineiras a 
fin de orientar o tecido urbano mediante unha ampla gobernanza dos proxectos agrícolas e agrourbanos. Ao radicar o reto social na calidade dos estilos de vida periurbano e rural, que non pode ser uniforme, as paisaxes están en condicións, daquela, de se converteren nun «carácter» socialmente distintivo dalgúns barrios da cidade e de partes do campo.

\section{Entre o mandato público autoritario e a autonomía local de decisión}

Presentados polos técnicos, urbanistas, arquitectos e paisaxistas, o mandato ou a invitación paisaxísticos fornecen sobre todo visións «formadas» e «informadas», externas aos territorios rurais. Depositarios dos valores das culturas urbanas, os produtores de normas paisaxísticas, ambientais e urbanas no marco de proxectos territoriais ofrecen, en primeiro lugar, unha información descendente (top down) desde o lexislador cara ao propietario, o arrendatario ou o usuario do espazo. Estas normas imporánselle por lei á persoa administrada; de non ser así, non producen efectos sobre a produción das paisaxes. Para que se poidan impor, os políticos nacionais e rexionais «consultan» os técnicos do Dereito antes de votaren sobre estas normas. De igual modo, cando a norma paisaxística se concibe a escala local, nos países da Unión Europea é obrigatorio que os servizos da Administración organicen un debate público, en aplicación da Convención Europea de Aarhus.

Cando son demasiado restritivas, as normas sobre a paisaxe e o contorno non poden aplicarse de maneira xusta; pero se resultan moi vagas, non xeran resultado ningún e son impotentes. Cando non se avalían, os seus resultados permanecen ignorados. Así, en Francia, a esixencia de obter unha "folla paisaxística» da licenza de obras evita, sen dúbida, graves erros, mais os técnicos do Estado seguen a ter moitas dificultades para xulgar estes documentos administrativos e a súa decisión, con frecuencia, é arbitraria, polo cal queda suxeita a litixios xurídicos e á intervención de peritos.

Nos mellores casos de toma de decisións públicas top down, dáse unha cooperación -ou máis ben unha transacción- entre quen fai aplicar os regulamentos locais nunha colectividade e o que debe aplicalos. O propietario dunha casa de futura construción, por exemplo, ha de adoptar as normas de altura e pendente dos teitos, ou as da forma das fiestras, sobre as que decidiron os cargos políticos dunha colectividade, aconsellados por un técnico de urbanismo. Estas 
normas tórnanse, xa que logo, nunha ferramenta de fabricación da identidade local das paisaxes urbanas da colectividade. Tales obrigas deben ser flexibles e permitir que o propio técnico, no nome do carácter do lugar que se vai crear, autorice a un arquitecto -por exemplo, de edificios públicos- a crear unha forma innovadora para fachadas e fiestras na mesma vila rural.

Por este motivo, o máis frecuente é que a gobernanza das paisaxes requira intercambio, codecisión e implicación dos interesados, tanto públicos como privados. Un camiño agrícola comunal suprimido ou privatizado por un agricultor pode crearse ou abrirse de novo, cando o solicitan os políticos para o destinar a usos de paseo. Poden reformarse sebes cedéndolle á colectividade os terreos agrícolas necesarios. Pódense acondicionar para uso público as marxes dos regatos e dos estanques, con ou sen compra posterior delas por parte da colectividade. A «publicitación» do espazo privado rural constitúe un proceso xeográfico que crea os bens comúns paisaxísticos. Deste xeito, somete o obxecto presentado a regras de civismo ou de cidadanía que varían moito dun lugar a outro, polo cal son frecuentes as tensións entre as persoas -actores públicos ou privados- que desexan instalar parques eólicos, criadeiros, vertedoiros, estradas, incineradoras, etc., e as que se ven afectadas por estas novas veciñanzas, consideradas molestas. Os riscos para a paisaxe e a contorna, apreciados polas "poboacións», avalíanse así nun proceso democrático que pode transformarse en proxecto de autodesenvolvemento sostible (Magnaghi, 2005).

A toma pública de decisións pode delegarse na colectividade local nun marco autónomo, sen que necesariamente se faga notar o peso do Estado. Neste marco de participación, ao que ás veces incitan as rexións de Europa, a regulación faise sobre todo bottom up. Os actores agrícolas poden abrir ao público os seus territorios para fins comerciais, permitir visitas aos seus viñedos ou hortos, propoñer produtos máis ou menos procesados, aloxar turistas, ofrecer servizos de ocio e restauración e facer dos valores da sostibilidade argumentos comerciais. O que non exclúe -ben ao contrario- que os servizos públicos controlen o carácter das paisaxes -en termos ambientais ou patrimoniais. Ademais, neste marco, as decisións públicas, tomadas polos actores locais e as organizacións non gobernamentais, adquiren unha maior lexitimidade social, pois chaman ao recoñecemento da expresión de proxectos individuais e colectivos, así como á súa xerarquización. 
Estes tres niveis de gobernanza, top down, bottom up e híbrida, organizan a interacción dos catro niveis de percepción da paisaxe en cada colectividade. Ás percepcións formadas pola arte, engádenselles as informadas pola influencia das ciencias; e ás percepcións polisensoriais da paisaxe por parte dos habitantes, o coñecemento dos proxectos dos actores agrícolas, cinexéticos e forestais. As gobernanzas que xestionan as decisións están, así, a cargo da xestión dun ir e vir permanente entre os intereses locais territorializados e os intereses colectivos e globais a escala planetaria. Deste xeito, as decisións tomadas interprétanse nas paisaxes percibidas e fabrican a identidade pública das colectividades, lonxe ou preto das respostas locais fornecidas para ter en conta os valores do desenvolvemento sostible. En consecuencia, unha paisaxe sostible -que é un proxecto posible de bens comúns sostibles- ha de expresar unha escolla perceptible sobre a creación de emprego e vivendas sociais, a conservación dos recursos naturais, a mesturanza do espazo público e a diversidade cultural dos grupos sociais. Cando ocorre o contrario, unha paisaxe pode traducir unha división por comunidades, unha segregación social, un desbaldir dos recursos enerxéticos, unha indiferenza diante da conservación ou a recreación da biodiversidade ou das molestias das proximidades.

Os niveis de responsabilidade política han ser de dominio público a fin de que, se os bens comúns que se deben crear non se teñen en conta a escala local, os organismos sociais adopten o recurso -a subsidiariedade- a un nivel superior de resposta colectiva -o Estado, a rexión, o grupo de comunidades. O mesmo pode dicirse se os poderes públicos, desde a comunidade ata o nivel internacional, non desempeñan o papel que se espera deles, o servizo do interese xeral.

\section{E a autenticidade das paisaxes agrícolas?}

Neste contexto democrático, a cuestión da autenticidade das paisaxes rurais presentadas regúlase tanto mediante a participación dos habitantes como a dos actores públicos a todos os niveis. En efecto, é auténtico o que se recoñece como verdadeiro e non como falsificación. Se unha colectividade admite que o seu campo debe resultar atractivo para os turistas e os habitantes e estar producido, sobre todo, por unha agricultura de servizos públicos paisaxísticos, tal colectividade proverase dos medios financeiros para fabricar o seu campo con este tipo 
de empresas, dirixidas aos consumidores da paisaxe e das actividades de lecer. A agricultura de pracer, a agricultura ecolóxica, a xardinaría e as políticas de zonas verdes periurbanas constitúen, entre outros, algúns dos medios lexítimos de xestión dos "parques agrourbanos» (Donadieu, 1998) ou os espazos de tipo "terceira paisaxe» ${ }^{4}$ que favorecen estas prácticas sociais.

Pola contra, se os actores agrícolas desexan perpetuar unha agricultura empresarial, dirixida en primeiro lugar ás bolsas de cereais de Chicago ou de Detroit, poden convencer os habitantes do rural da identidade auténtica das paisaxes de cultivos de cereais así producidas. Resultaralles máis doado facelo se son viticultores e produtores de viños con DOC, especialmente se operan nas paisaxes culturais incluídas na lista do patrimonio mundial da UNESCO: en Cinque Terre (Liguria) ou Saint-Emilion (Bordeos). Cando as imaxes da paisaxe entran na mediación paisaxística, presentan os elementos estetizándoos ou documentándoos, e non afeándoos. Neste sentido, adoitan ser parciais -nos dous significados da palabra-, mais sacan á luz o que é descoñecido e non desexa seguir séndoo. Toda paisaxe é estetizable, o cal lles encanta ás visións formadas, pero debe ser tamén obxecto de influencias informadas e de documentación se o espectador pretende ir alén das aparencias, o que implica a presenza das outras visións: as «iniciadas», as «informadas» e as «incorporadas»; e iso implica tamén a presenza doutros valores éticos na transmisión da paisaxe ás xeracións futuras, como os do desenvolvemento sostible.

\section{$\mathrm{O}$ que din ao respecto os investigadores franceses}

Reunidos recentemente, en abril de 2008, en Versalles para honrar a memoria de Jean-Pierre Deffontaines, xeoagrónomo pioneiro da investigación agronómica das paisaxes agrícolas, os investigadores confirmaron as evolucións arriba indicadas.

$\mathrm{Na}$ actualidade, o $60 \%$ do territorio francés está destinado a usos agrícolas e, para o xestionar, cada vez existen menos agricultores e dáse unha demanda residencial e turística cada vez maior para acadar unha mellor habitabilidade do

\footnotetext{
${ }^{4}$ Segundo o paisaxista Gilles Clément, trátase de espazos que carecen doutros usos sociais que non sexan os de acadar unha biodiversificación sostible a escala local e global.
} 
campo -accesibilidade para as actividades de lecer e superior calidade de vida. Fronte a esta demanda social de calidade das paisaxes, os científicos admiten que a noción de "paisaxe» é tanto unha percepción humana e unha representación do espazo como un espazo material obxectivo. A relación existente entre estes dous polos, o subxectivo e o obxectivo, fai do campo un obxecto de desexo social, mais non hai consenso sobre o que deben ser estas paisaxes, que se tornan así en desafíos sociais, sobre todo para as políticas públicas agrícolas e paisaxísticas. Uns insisten na paisaxe como produto -en permanente evolucióndas actividades agrícolas, e como reflexo das políticas públicas nas que se enmarcan estas; outros, nos vínculos comerciais que se deben establecer entre a calidade dos produtos agrícolas - por exemplo viños e queixos- e as paisaxes que os producen. A maioría coincide en constatar que, no período produtivista da agricultura administrada, a forma das paisaxes disociouse do medio natural e humano que as producía, e que resulta indispensable restablecer este vencello que descoidaran os agrónomos e os agricultores. Entre a agricultura de servizos e a agroindustria, algúns recomendan a agricultura rexional ligada á valoración e á conservación dos recursos locais -enerxía, auga, solo, medios naturais-e aos valores do desenvolvemento sostible. Outros identifican o xurdimento de novos colectivos agrícolas e non agrícolas aos que lles incumbe a valoración dos espazos marxinados pola agroindustria; por exemplo, recuperación das terrazas agrícolas abandonadas, das zonas húmidas ou dos ermos postindustriais e urbanos.

Faise tamén a constatación de que as calidades do nivel de vida rural -a pureza do aire e da auga, a limpeza dos solos, a riqueza da biodiversidade, o atractivo das escenas paisaxísticas, a diversidade do patrimonio histórico, a facilidade de acceso- son fonte dun maior benestar tanto dos habitantes -incluídos os agricultores- como dos turistas. Estas calidades soñadas, frecuentemente mitificadas, fan do campo un refuxio antiurbano e un lugar nostálxico de solidariedade social e de benestar humano. Os científicos, referíndose ás investigacións agronómicas sobre a nutrición humana, que amosaron a importancia da percepción sensorial -o sabor- dos alimentos, coidan que os traballos dos investigadores agrónomos deben centrarse a partir de agora na percepción das paisaxes, eido que xa exploraron os sociólogos, os etnólogos e os xeógrafos. O proxecto paisaxístico, familiar para os paisaxistas, preséntaselles como unha ferramenta de cualificación global das paisaxes en evolución e como un medio 
local de levar á practica un sistema de gobernanza dos proxectos territoriais cos actores locais.

\section{CONCLUSIÓN}

As sociedades rurais europeas arríscanse a quedar divididas en catro categorías de relacións cos espazos agrícolas e arborados: favorecer a agricultura e a xardinaría de servizos a escala local, máis que as destinadas aos produtos agroindustriais que conveñan ás prácticas residenciais, turísticas e de lecer, nos espazos «rurbanos» multifuncionais integrados nas rexións urbanas e destinados a permanecer alí. Favorecer o mantemento de agroindustrias que despachan produtos a escala local e mundial nas rexións agrícolas mecanizables e que acotío carecen de actividades de ocio e prácticas turísticas ou de descanso na vila. Facer isto mesmo lonxe das cidades, nas zonas agrícolas pouco favorables para a mecanización -montañas, zonas húmidas-, recorrendo á agricultura de servizos, financiada polas colectividades e por Europa e destinada a limitar as plantacións forestais e os riscos -incendios, erosión, inundacións- e a favorecer as economías residenciais e turísticas. Ou ben, finalmente, nos tres casos anteriores, recorrendo aos valores do desenvolvemento sostible, a fin de poñer en marcha proxectos rexionais desde unha perspectiva de autodesenvolvemento sostible localizado.

Segundo sexan as producións e os seus proxectos, os agricultores veranse, pois, en dúas situacións moi diferentes: ou pretenderán resistirse ao proxecto paisaxístico público e sostible escapando del -deslocalización fóra de Europa ou lonxe das cidades-, ou ben o integrarán nas súas actividades comerciais para facer del, xunto cos habitantes dos territorios e rexións agrícolas, un activo local para o desenvolvemento sostible. Corresponderalles aos poderes públicos das colectividades, especialmente as urbanas, atopar as regras de gobernanza necesarias para elixir e enmarcar estas mudanzas. 


\section{BIBLIOGRAFÍA}

Donadieu, P.: La société paysagiste, Actes Sud/ENSP Versailles, 2002. [Hai edición en castelán].

Donadieu, P.: «De l'utopie à la réalité des campagnes urbaines», Urbanistica, n. ${ }^{\circ} 128,2006 a$, p. 15-20.

DONADIEU, P.: «Landscape urbanism in Europe: from brownfields to sustainable urban development», JoLA (Journal of Landscape Architecture), n. ${ }^{\circ}$ 2, Autumn, 2006b, p. 36-45.

DONADIEU, P.: «Le paysage, un paradigme de médiation entre l'espace et la société», Economie rurale, n. ${ }^{\circ}$ 297-298 (introduction d'un dossier «Paysage»), 2007.

Donadieu, P. e E. MaZas: Des mots de paysage et de jardin, Dijon, Edisud, 2002.

Donadieu, P. e M. PÉrigord: Clés pour le paysage, Gap, Ophrys, 2005.

Donadieu, P. e M. PÉRIgORD: Le paysage entre nature et culture, Paris, A. Colin, 2007.

Magnaghi, A.: The urban village, a charte for democracy and local self sustainable development, London/New York, Zed Books, 2005. 